\title{
Analysis of electric power generation characteristics for hybrid power system
}

\author{
J.J. YANG \& B. Qu \& L.M. Jiang \\ China Electric Power Research Institute, Beijing 100192, China
}

L. Lei \& L. Chen \& W.Q. Tao

Key Laboratory of Thermo-Fluid Science and Engineering, Ministry of Education, Xi'an Jiaotong University, Xi'an710049, China

Y. Qi

State Grid Tianjin Electric Power Research Institute, Tianjin, China

\begin{abstract}
Based on micro gas turbine, a wind-solar-gas complementary system was presented to explore efficiently method of new energy utilization. The output characteristics of photovoltaic power and wind power generation were introduced in detail, and the power output according to the corresponding influence parameters is also calculated; the power parameters of wind power, photovoltaic power generation as well as complementary power generation system are determined based on wind speed and illumination intensity data. The results show that: the complementary function can be realized in the local electric network by the proposed system and the sum of capacity coefficient of wind power, photovoltaic power generation and gas turbine power generation approximate to 1 . Therefore, the proposed complementary system provides the basis of technical and economic analysis to achieve an area complementary power generation.
\end{abstract}

KEYWORD: Wind Power; Photovoltaic; Complementary Power Generation System; Characteristic Parameters; Capacity Factor

\section{INTRODUCTION}

With the serious problem of environmental pollution caused by the rapid development of global economy, wind and solar photovoltaic power have emerged as two of the most attractive clean technologies and they are planned to be major sources of future electricity needs (An, X.T. et al. 2013, Bao, N.S. et al. 2007, Bao, N.S. et al. 2006). As the basic industry of national economy, energy is not only the necessary premise to ensure the national strategic security, but also an important guarantee of realizing economic sustainable development. Hybrid energy power generation system is one of the important measures to promote clean energy use to reduce energy consumption, increase efficiency and to reduce greenhouse emissions. On the one hand, the implementation of hybrid energy complementary power generation system can effectively improve energy efficiency of the end user, relieve the contradictions of supply and demand of regional power grid, promote the distributed renewable energy in place consumption, while maximizing regional power grid load shifting. Many kinds of complementary energy system were put forward at home and abroad, such as Solar-Thermal power system (Chen, Y et al. 2009, Del Granado, P.C. et al. 2016), Wind- Solar power generation complementary system (Fathima, A.H. et al. 2015),
Compressed air energy storage system-Wind-Diesel power generation system-Wind-Hydrogen energy storage system-Wind-High temperature fuel cell power generation system (Gao, Z. et al. 2014, Giraud, F. et al. 2001 ), etc. However, these system has some limitations under the condition of existing technology. On the other hand, Solar and wind energy is the most common and the most common natural resources, also the inexhaustible clean energy, utilization of solar energy and wind power reasonably will be advanced greatly in energy conservation and environmental protection problem (Ismail, M.S. et al. 2015). But as a special power, the utilization of wind power and photovoltaic power is affected at season, geography, weather and many other factors, it has very strong complementarity on the time and place, also has many different characteristics from the conventional energy generation (Li, C.B. et al. 2011). With the expansion of the wind power and photovoltaic power, the influence on power-grid is more and more significant, also becoming an obstacle to the scale development of wind power and photovoltaic battery capacity.

In this paper, combining with the characteristics of wind and solar, using the technology of wind power and photovoltaic power comprehensively (Medsker, L.R. 2012), established a Wind-Solar- 
Gas-Storage complementary system. Studied the output characteristics of wind power, photovoltaic power generation and gas turbine power generation based on the hybrid energy output complementary system, calculated the system output, capacity coefficient, the number of using-hours of the year and other corresponding characteristic parameters, finally analyzed the results.

\section{HYBRID ENERGY COMPLEMENTARY POWER GENERATION SYSTEM}

The hybrid energy complementary power generation system as shown in Figure 1, the fundamental part is energy storage systems, power generation and load system, and what makes up the area network are wind power, photovoltaic power, gas turbine power and energy storage system, and the photovoltaic, wind power and gas turbine power are the major form of supplying cold, hot and electricity load, energy storage system as the auxiliary part

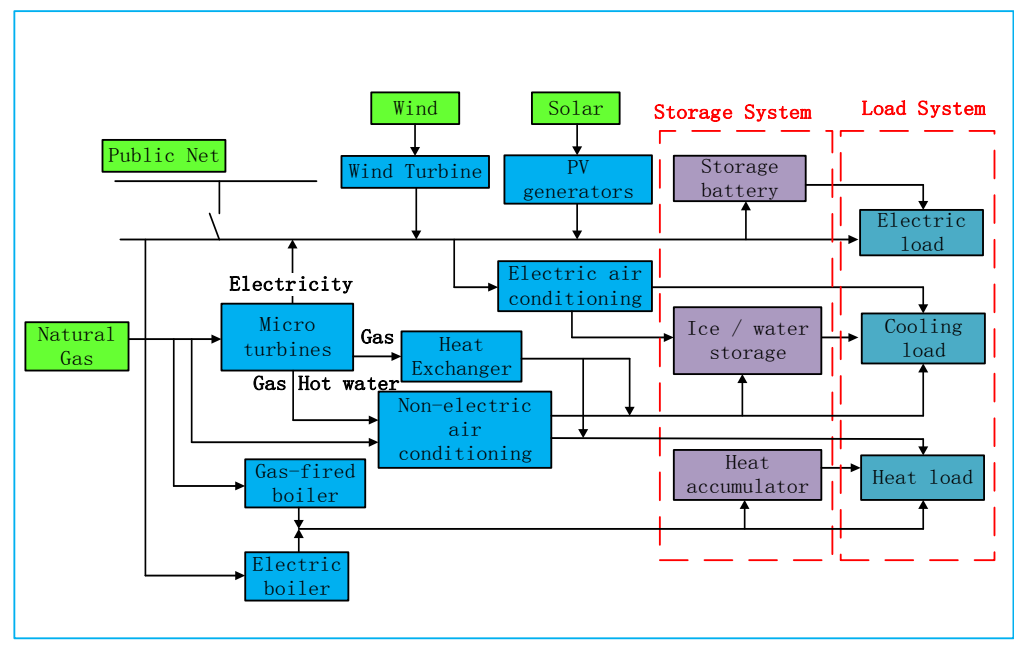

Figure 1. Hybrid energy complementary power generation system

Generally, the power supply mode is run in offnet mode, it is not connected to the public supply network, but in a terrible external conditions, such as the bad weather, can be assisted by energy storage system to ensure the most important sensitive load supplied uninterruptedly. In the off-net mode, the three kinds generating units of micro gas turbine, wind power and photovoltaic power supplying the cold -hot-electricity load of system . The electric boiler generates thermal energy providing the heat load, when the heat power is enough and then can be stored for the heat load peak using; Real-time Electric air conditioning is refrigerating timely, and the cold power can be stored when it is very sufficient for the peak season using. At the same time, the high temperature flue gas and hot water of the gas turbine can also make heating and cooling power for the load of system by using heat exchanger and nonelectric air conditioning. When a fault has occurred of system, it would be connected to the public power distribution network for power supplying, can also satisfy the cold-hot-electricity load.

\section{OUTPUT CHARACTERISTIC ANALYSIS FOR HYBRID ENERGY}

\subsection{Wind power characteristics}

Wind power is clean energy, and rational use of wind energy can effectively improve the load state of the power system. In the peak period, wind turbine units supply the regional power net to meet the prevailing electric load; when low power consumption, wind energy from turbine units can be sent for storage to prepare for peak use.

But wind energy has intermittency, volatility and randomness, which determine the wind power output may change dramatically, also making the presence of the power system frequency stability and voltage stability problems. In order to ensure power system stability and power balance, there must be other form for wind power frequency modulating and peaking, and its performance can be met the needs of wind power.

For good use of wind energy, the output characteristics of wind turbine must be analyzed. So, in this paper wind turbine output power variation characteristic curve is set as research subjects, where the wind speed is the most important factor. Output of wind turbine is determined by the average wind speed at the height of the fan shaft and output char- 
acteristics of the fan, the fan output is expressed as follows:

$$
P_{W G}= \begin{cases}0 & v \leq v_{\text {in }} \text { 或 } v \geq v_{\text {out }} \\ \frac{v^{3}-v_{\text {in }}{ }^{3}}{v_{r}{ }^{3}-v_{\text {in }}{ }^{3}} P_{\text {rate }} & v_{\text {in }} \leq v \leq v_{r} \\ P_{r}, & v_{r} \leq v \leq v_{\text {out }}\end{cases}
$$

Where: vin is cut-in wind speed, $\mathrm{m} / \mathrm{s}$; vout is cut-out wind speed, $\mathrm{m} / \mathrm{s}$; PWG is the output power of wind turbine, $\mathrm{kW}$; Prate is rated power output of the wind turbine, $\mathrm{kW} ; \mathrm{v}$ is the wind speed at a height of turbine hub, $\mathrm{m} / \mathrm{s}$. Figure 2 shows the relationship between wind turbine output power and wind speed.

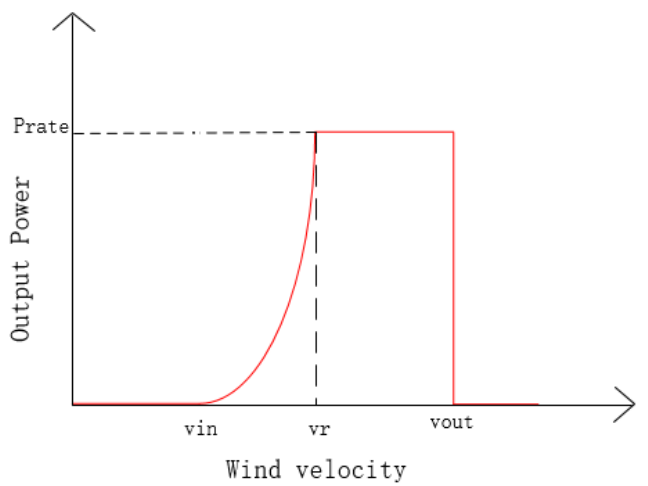

Figure 2. Relation curve of output power and wind speed

Figure 3 and Figure 4 are respectively average wind speed distribution in May 2015 Shanghai of a day and a whole month of 31 days. It can be seen not only at different times of day, wind speed fluctuations, also in the entire 31 days, the daily wind speed varies widely. It is possible to know the characteristics of wind turbine output in the short term and the long term will also vary widely.

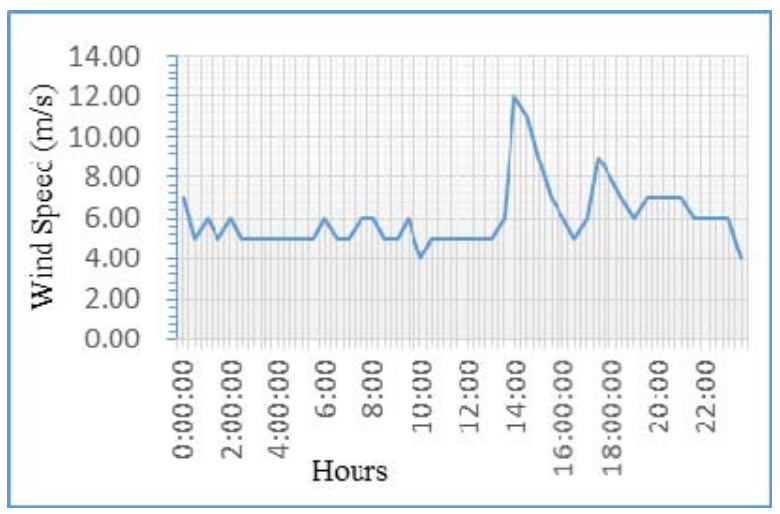

Figure 3. wind speed distribution in one day

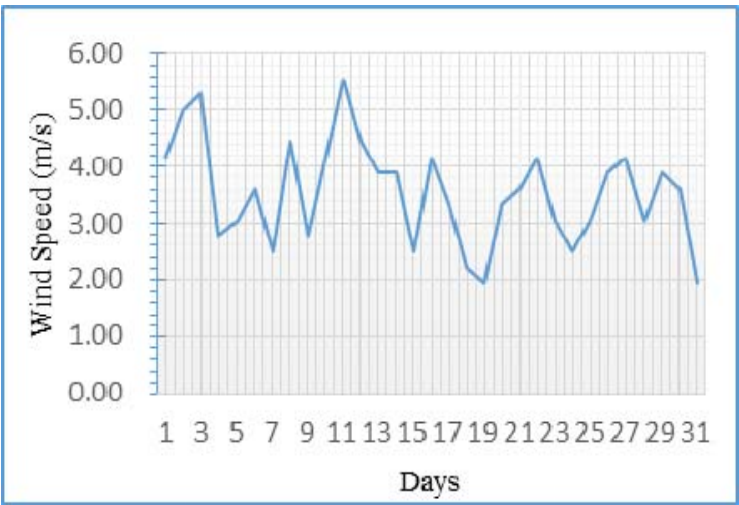

Figure 4. Wind speed distribution in a month

The output power can be obtained respectively by definition corresponding to the wind speed. Select WT2000-D103 wind turbines rated at 2MW, cut in wind speed is $3 \mathrm{~m} / \mathrm{s}$, cut-out wind speed is $20 \mathrm{~m} / \mathrm{s}$, rated wind speed $9.5 \mathrm{~m} / \mathrm{s}$, wind power output curve shown in Figure 5 and Figure 6.

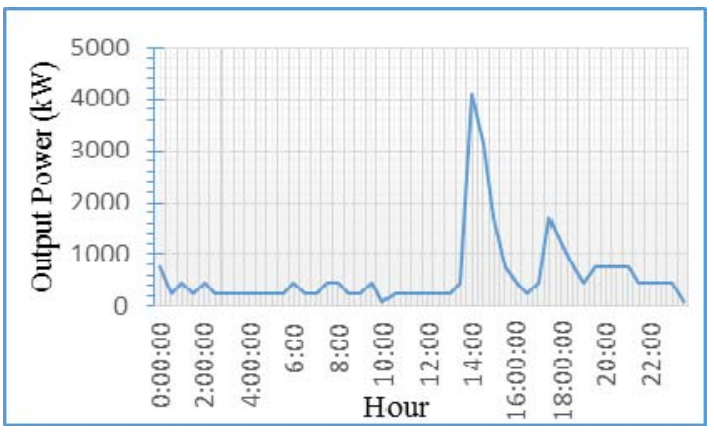

Figure 5. Output power distribution in one day

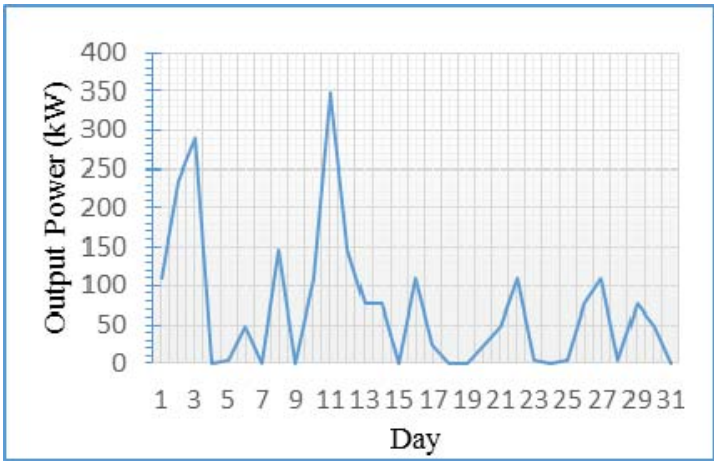

Figure 6. Output power distribution in a month

As shown in Figure 5, the output power of wind turbines at different time in one day have greater volatility, especially reaching a maximum value at two pm. And from the whole 31 days, the daily power output and adjacent days is very different. That is to say, wind power is volatile and intermittent. Thus, only with other power supply for peak regulation and frequency adjustment can provide considerable power. 


\subsection{Photovoltaic power characteristics}

Solar energy is a green and new sustainable utilization energy, photovoltaic (PV) is the main form of solar energy utilization. At present, solar photovoltaic power generation is developing from independent small home systems to large-capacity power plant and network, and will generate affect that cannot be ignored. Photovoltaic power generation has many features, such as no pollution, no noise, no fuel consumption, safety and reliability and easy maintenance, etc. But solar power is unstable and solar radiation intensity is not same at each time on the same day and same space. At the time of sunrise and sunset, the intensity of solar radiation is much smaller than around midday; also in different seasons of the same place is not the same, on the middle and high latitudes is much stronger than in summer and winter. Solar also has intermittent, direct solar radiation is alternating day and night change significantly.

PV output power is defined as follows:

$$
P_{p V}=P_{S T C} G_{A C} \frac{\left(1+k\left(T_{c}-T_{r}\right)\right)}{G_{S T C}}
$$

Where: Ppv is output power of photovoltaic cell; GAC is light intensity; PSTC is maximum test power in standard test conditions (sun incident intensity is $1000 \mathrm{~W} / \mathrm{m} 2$, ambient temperature is $25{ }^{\circ} \mathrm{C}$ )GSTC $=1000 \mathrm{~W} /(\mathrm{m} 2 \cdot \mathrm{k}) . \mathrm{k}$ is the temperature coefficient of the power, Tc is the panel temperature, $\mathrm{Tr}$ is the reference temperature.

It can be seen, the power output of photovoltaic cells vulnerable to the impact of external weather, the stochastic changes of outside temperature and solar radiation intensity make the PV output power have randomness and unevenness, for the rational use of solar energy, it is very necessary to study the random distribution of the light intensity of the sun.

The sun radiation is shown in Figure 7 at somewhere in a typical day of August. As can be seen from the figure, the light intensity is very different at different times of the same day, light intensity is substantially zero at night; From 6:00 am to 12:00 noon, light intensity increased significantly, at 12:00 - 18:00 in the evening, and the light intensity decreases rapidly. So for photovoltaic power plants, the power output of daytime will be maximum value at noon, while at night is substantially zero.

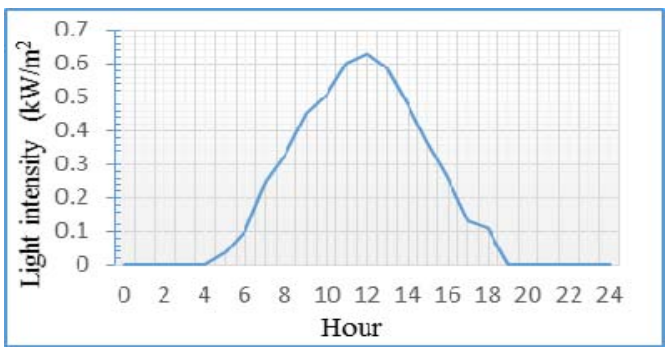

Figure 7. Light intensity distribution at every time

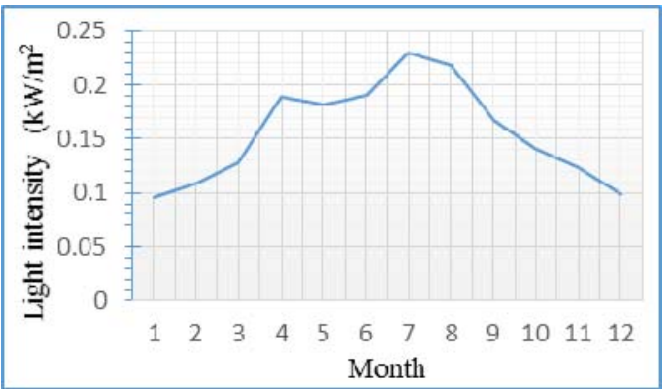

Figure 8. Light intensity distribution at every month

Figure 8 is a monthly average light intensity in different months of the same year. Overall, the light intensity in the first quarter and the fourth quarter is smaller compared with the second and the third quarter, especially the light intensity reached a maximum value of $0.23 \mathrm{~kW} / \mathrm{m} 2$. Obviously, such a light intensity distribution is in line with the actual natural conditions.

Under standard test conditions to take maximum test power as PSTC $=2000 \mathrm{~kW}$, calculated PV output power according to the formula (2), the results are shown in Figure 9 and Figure 10. The trend of PV power output and light intensity changes are similar, the PV plant output power is distributed substantially 6:00 20:00, the maximum output power appears at noon; And its power output is also fluctuating with season change. In June and August, due to the long exposure time and light intensity are relatively strong, at this time power output is larger compared to it in other months.

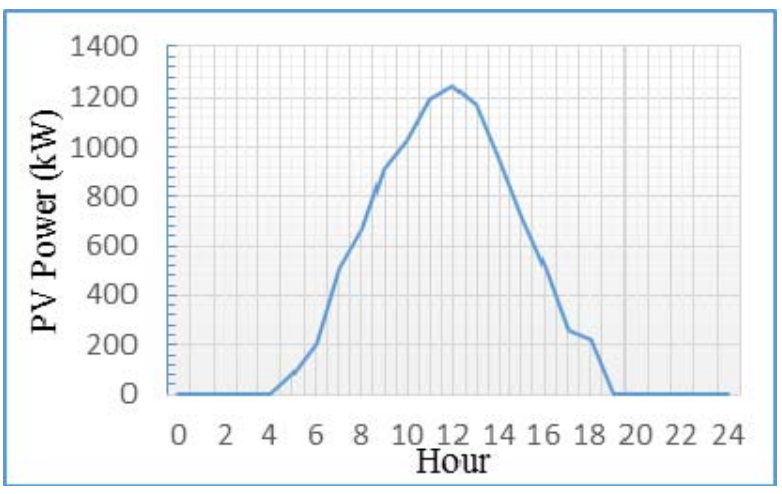

Fig.9 PV output power distribution of hour

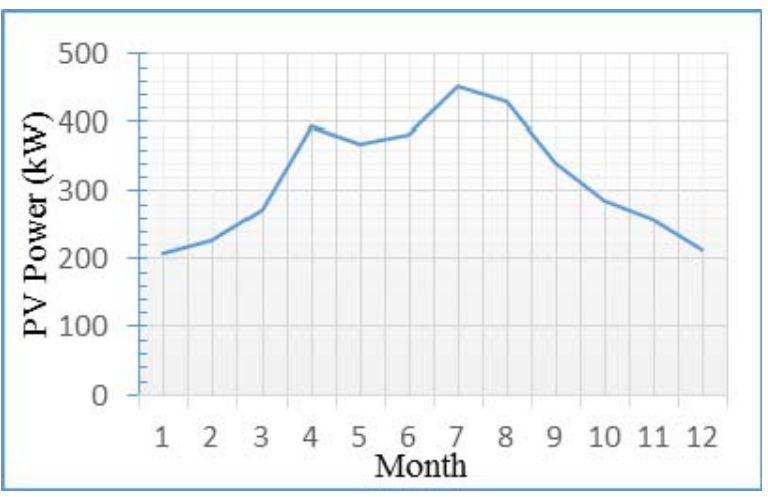

Fig.10 PV output power distribution of month 
Therefore, accessing photovoltaic power plants to the regional power net, can smooth the local load curve and reduce the peak load difference. But alone PV system cannot directly supply the load, because there is no self-regulation, when the large-capacity systems connected to the grid, it cannot bear the frequency and voltage regulation task like a regular generator, as light intensity changing substantially it also will result in output power instability. To resolve this issue is to add the appropriate capacity of the energy storage device in the power generation system, and make electric power balance by energy storage device.

\subsection{Gas turbine operating characteristic}

In general, the power range of gas turbine is $500 \mathrm{~kW}$ $-250 \mathrm{MW}$. More suitable for the complementary energy system consisted of wind power generation and photovoltaic power generation is mainly micro gas turbines, which power range is $1-40 \mathrm{MW}$. Micro-turbine power generation system comprises a permanent magnet synchronous generator, the micro-turbine, power electronic conversion device, heating and refrigeration units. When the gas turbine, air is compressed by the compressor and getting a high-pressure, natural gas is combusting in the combustion chamber and air is heated to a high temperature, and then expanded in a turbine to do work, a portion of the work drive the compressor, the other portion output shaft work to the power generator, then output the power, at last flue gas discharged. In order to recover high temperature flue gas heat, it tends to add a heat recovery system, using hightemperature flue gas to generate heat power. Also can use the high-temperature exhaust gas to preheat the compressed air into the combustion chamber, improving energy utilization efficiency of the system. Exhaust gas from heat regenerator can meet demand of the heating load by lithium bromide chiller or heat exchanger. Gas turbine drive the permanent magnet synchronous generator made by high-energy permanent magnet materials, which produces a high frequency alternating current, and changed into power frequency current by power electronic converter.

Output power is defined as follows:

$$
\begin{aligned}
& P_{M T}=\rho V_{i n}(t) L H V_{f}+C_{p} \rho V_{i n}(t)\left(T_{2}(t)-T_{1}(t)\right) \\
& P_{M T}^{\prime}=\operatorname{cop} C_{p} \rho V_{e x}(t)\left(T_{2}(t)-T_{3}(t)\right)
\end{aligned}
$$

Where: PMT is output power of run full working conditions; Vin is the flow rate of intake air; P'MT represents recovered heat; LHVf is low calorific value; Vex is exhaust flow rate; cop is thermal coefficient; T1 is intake air temperature; T2 is exhaust gas temperature; T3 is outlet temperature of saturated steam; $\rho$ is the density of the gas; $\mathrm{Cp}$ is the specific heat capacity.
In summary, the output characteristics of wind power and photovoltaic power generation have strong differences in time and space, but these differences provided favorable conditions for complementary feature of the complementary power generation system. Therefore, these differences can be effectively utilized to achieve the complementary power generation, to play the role of "load shifting" and to stabilize voltage output.

\section{CHARACTERISTIC PARAMETERS}

According to the working and output characteristics of wind power, photovoltaic power generation and gas turbine, can calculate some characteristic parameters related to economic analysis of hybrid power system. Such as the System capacity, natural gas consumption, capacity factor, annual utilization hours and the gas turbine efficiency.

\subsection{System capacity}

a. The total installed capacity (Pm) of complementary system are:

$P_{m}=P_{m_{-} w}+P_{m_{-} \mathrm{s}}+P_{m_{-} \mathrm{g}}$

Where: $\mathrm{Pm} \_\mathrm{w}$ is total installed capacity of wind farms; Pm_s is total installed capacity of photovoltaic power plant; Pm_g is total installed capacity of gas Turbine power plant.

b. The total generating capacity of complementary system for a certain amount of time Em:

$$
E_{m}=E_{\mathrm{e}_{-} \mathrm{w}}+E_{e_{-} \mathrm{s}}+E_{e_{-} \mathrm{g}}
$$

Where: Ee_w is total generating capacity of wind farms in a period of time; Ee_s is total generating capacity of photovoltaic power plant at a time; Ee_g is total generating capacity of gas turbine power plants in a period of time; while:

$$
\left\{\begin{array}{l}
E_{e_{-} w}=\int_{t=0}^{T} P_{w}(t) d(t) \\
E_{e_{-} s}=\int_{t=0}^{T} P_{e}(t) d(t) \\
E_{e_{-} g}=\sum_{i=1}^{n_{g}} E_{e_{-} g, i}=\sum_{i=1}^{n_{g}} \int_{t=0}^{T} P_{g, i}(t) d(t)
\end{array}\right.
$$

Where: $\mathrm{t}$ is a time variable; $\mathrm{T}$ is the time period; $\mathrm{Pw}(\mathrm{t})$ is wind farm power generation at time $\mathrm{t}$; $\mathrm{Pe}(\mathrm{t})$ is PV field generated power at time $\mathrm{t}$; ng is gas turbine station number; Ee_g, $i$ is the total generating capacity of the i-th gas turbine in a period of time; $\mathrm{Pg}, \mathrm{i}(\mathrm{t})$ is the total generating capacity of the $\mathrm{i}$-th gas turbine power generation at time $t$.

\subsection{System capacity}

Total natural gas consumption of micro turbine power plant is defined as follows: 
$G_{g a s}=\sum_{i=1}^{n_{g}} G_{g a s, \mathrm{i}}$

Where: Ggas,i is the natural gas consumption of the $\mathrm{i}$-th gas turbine.

$G_{g a s, \mathrm{i}}=\frac{\int_{t=0}^{T} \frac{P_{g, i}(t)}{\eta_{g, i}(t)} d(t)}{E_{g a s}}$

Wherein, Egas is the heating value per cubic meter of natural gas, the standard calorific value of the gas selected as: Egas $=349902 \mathrm{~kJ} / \mathrm{m} 3 ; \eta \mathrm{g}, \mathrm{i}(\mathrm{t})$ is the $\mathrm{i}$-th gas turbine power generation efficiency of partial load, it defined as:

$\eta_{g, i}(t)=f\left(L_{g, i}(t)\right)$

Wherein, $\mathrm{Lg}, \mathrm{i}(\mathrm{t})$ is the partial load percentage of the $i$-th gas turbine; $f(\mathrm{Lg}, \mathrm{i}(\mathrm{t}))$ as the function of power generation efficiency and the partial load.

Therefore, the average gas consumption per unit $\mathrm{kWh}$ can be defined as follows:

$\bar{g}_{g a s}=\frac{G_{g a s}}{E_{e_{-} g}}$

\subsection{Capacity factor}

Capacity factor $(\beta)$ is an important parameter for representing a power generation equipment utilization efficiency, it defined as: within a year, the ratio of the total generating capacity Ee from a given equipment and the maximum generating capacity (Emax) of the device of maximum output power at the same time.

$\beta=\frac{E_{e}}{E_{\max }}=\frac{\int_{t=0}^{T} P(t) d(t)}{P_{n} T}$

In the above formula: $\mathrm{P}(\mathrm{t})$ is the power of generating units; Pn is rated power for the unit.

The power $(\mathrm{Pm})$ of hybrid generating system is the sum of total output power of wind farms $(\mathrm{Pw})$, total power output of photovoltaic power plants (Ps) and the total output power of gas turbine plants $(\mathrm{Pg})$. $P_{m}=P_{w}+P_{s}+P_{g}$

Therefore, the capacity factor of wind farms, PV fields and gas turbine can be expressed as $\beta \mathrm{w}, \beta \mathrm{s}$ and $\beta \mathrm{g}$, it defined as follows:
$\left\{\begin{array}{l}\beta_{w}=\frac{E_{e_{\_} w}}{E_{\text {max } \_ \text {w }}}=\frac{\int_{t=0}^{T} P_{w}(t) d(t)}{P_{n_{-} w} T} \\ \beta_{s}=\frac{E_{e_{\_} s}}{E_{\max _{\_} s}}=\frac{\int_{t=0}^{T} P_{s}(t) d(t)}{P_{n_{-} s} T} \\ \beta_{g}=\frac{E_{e_{\_} g}}{E_{\max \_g_{-}}}=\frac{\sum_{i=1}^{n_{g}} \int_{t=0}^{T} P_{g, i}(t) d(t)}{\sum_{i=1}^{n_{g}} P_{n_{-} g, i} T}\end{array}\right.$

Wherein, Pn_w is the rated power of wind turbine; Pn_s is the rated power of photovoltaic unit; Pn_g is the rated power of gas turbine unit.

Accordingly, the average capacity factor $(\beta \mathrm{m})$ of the complementary power generation system is defined as follows:

$\beta_{m}=\frac{E_{m}}{E_{\max \__{-} m}}=\frac{E_{e_{-} w}+E_{e_{-} s}+E_{e_{-} g}}{E_{\text {max } \_w}+E_{\max \_s_{-s}}+E_{\max \__{-} g}}$

Obtained:

$\beta_{m}=P_{w} \beta_{w}+P_{s} \beta_{s}+P_{g} \beta_{g}$

Where: $\mathrm{Pw}$ is the percentage of wind farm capacity and the total system capacity of complementary power generation; Ps is the percentage of photovoltaic power generation capacity and the total system capacity of complementary power generation; Pg is the gas turbine power plant capacity accounted for complementary total generating system capacity percentage ratio.

\subsection{Annual utilization hours}

Annual utilization hours is defined as:

$\tau=N_{y} \bullet \beta$

Wherein, Ny is the total number hours of a year, equivalent to 8760 hours. So we can define the respective annual utilization hours of wind farm, photovoltaic power and gas turbine:

$\left\{\begin{array}{l}\tau_{w}=N_{y} \cdot \beta_{w} \\ \tau_{s}=N_{y} \cdot \beta_{s} \\ \tau_{g}=N_{y} \bullet \beta_{g}\end{array}\right.$
$\tau_{m}=N_{y} \cdot \beta_{m}$
$=N_{y} \cdot\left(P_{w} \beta_{w}+P_{s} \beta_{s}+P_{g} \beta_{g}\right)$
$=P_{w} \tau_{w}+P_{s} \tau_{s}+P_{g} \tau_{g}$

\subsection{Gas turbine efficiency}

The average efficiency of the micro-turbine is defined as follows:

$\eta_{g}=\frac{\beta_{g} P_{n_{-} g}}{G_{g a s} E_{g a s}}$ 
The average efficiency of the $\mathrm{i}$-th gas turbines is defined as follows:

$\eta_{g, k}=\frac{\beta_{g, k} P_{n_{-} g, k}}{G_{g a s, k} E_{g a s}}$

\section{RESULTS ANALYSIS}

According to the above formulas, selected 25 wind generators and the model is WT2000-D103 (rated at $2 \mathrm{MW}), 35 \mathrm{PV}$ arrays which maximum test power
PSTC is 2MW under standard test conditions and two gas turbines which rated capacity are $40 \mathrm{MW}$, constituted the hybrid power systems, and calculated key performance parameters of the entire complementary power generation system, the results are shown in Table 1.

Table 1. key performance parameters of complementary system

\begin{tabular}{|c|c|c|c|c|}
\hline & $\begin{array}{l}\text { Wind } \\
\text { power }\end{array}$ & $\begin{array}{r}\mathrm{PV} \\
\text { power }\end{array}$ & $\begin{array}{l}\text { Gas turbine } \\
\text { power }\end{array}$ & $\begin{array}{l}\text { Complemen- } \\
\text { tary power }\end{array}$ \\
\hline Rated Capacity $\mathrm{I}_{w / s / g, i}(\mathrm{MW})$ & 2 & 2 & 40 & - \\
\hline Number of units $n_{w / s} / g$ & 25 & 35 & 2 & - \\
\hline Installed Capacity $\mathrm{P} m \_w / s / g \quad （ \mathrm{MW} ）$ & 50 & 70 & 80 & - \\
\hline Annual generation capacity E E_w/s/g $(\mathrm{GWh})$ & 157.98 & 87.2 & 464 & - \\
\hline Average Capacity Factor $\beta$ w/s/g/m & 0.259 & 0.142 & 0.61 & 0.358 \\
\hline Annual utilization hours $\tau$ w/s/g/m $(h)$ & 2269 & 1246 & 5344 & 2667.9 \\
\hline Total consumption of NG Ggas $\left(\mathrm{Mm}^{3}\right)$ & - & - & 131.5 & - \\
\hline Average efficiency $\eta$ gas $\quad(\%)$ & - & - & 36.40 & - \\
\hline Total Installed Capacity $\mathrm{P}_{m}$ (MW) & - & - & - & 200 \\
\hline Total Generating Capacity $\mathrm{E}_{e}(\mathrm{GWh})$ & - & - & - & 709.18 \\
\hline
\end{tabular}

Among the parameters listed in the table1, the total generating capacity, the average capacity factor and the average utilization hours are the most important especially. It found that the capacity factor of a separate wind-power generator is about 0.3 within a year, photovoltaic power generation capacity factor is 0.14 , gas turbine power generation capacity factor is 0.61 , the three value approximately equal to the sum of 1 , namely: $\beta \mathrm{w}+\beta \mathrm{s}+\beta \mathrm{g}=1$. The average capacity factor of complementary system is 0.358 , and it is much smaller compared to a single gas turbine power generation, but close to a single wind power, photovoltaic power generation capacity factor is minimal. Moreover, PV and wind power utilization hours is also minimal, which is leaded by their intermittent and instability on the season and time. The total generating capacity of hybrid systems and annual utilization hours have been improved, which also shows that wind-solargas hybrid power system is really beneficial for improving power supply. As can be seen from the results of $\beta \mathrm{w}+\beta \mathrm{s}+\beta \mathrm{g}=1$, when the capacity factor of wind power and photovoltaic power generation grows, it can reduce the gas turbine's capacity factor, that is, in the light resources and wind resources more fully, you may use a gas turbine power generation which capacity is relatively small, so also reduces the consumption and the purchase price of natural gas. According to such a relationship, in the case of the specified amount of electricity generated, you can select the appropriate relationship of the ra- tio of capacity, so that investment costs can be the minimum.

\section{CONCLUSION}

Proposed a wind-solar-gas complementary energy power generation system based on micro-turbine hybrid, and calculated the performance parameters of wind power, photovoltaic power and gas turbine power generation according to the corresponding affecting parameters, the results showed that: The established complementary energy power generation system can achieve the purpose of power complementary of regional electricity net; the capacity factors of wind power, photovoltaic and gas turbine power generation are approximately equal to 1 , and provides a theoretical basis for technical analysis and economic analysis to realize regional power grid.

The formulas of the performance parameters and the corresponding parameters obtained in this paper will play a very important role in studying the realtime control and optimize allocation of the complementary system in the future. In an area where wind energy and solar energy are very rich, the utilization of the complementary power generation system can effectively improve the power supply, and reduce the use of natural gas, also can achieve the purposes of energy saving. 


\section{ACKNOWLEDGEMENTS}

This work was supported by the National High Technology Research Development Program of China (863 Program) (2015AA050403), the State Grid Company Science Technology Program (SGTJDK00DWJS1500100).

\section{REFERENCES}

An, X.T. et al. 2013. Simulation of energy off-grid power generation systems scenery mixing [J]. Computer Simulation, 2013, 30(8): 116-121.

Bao, N.S. et al. 2007. Research on wind power and gas turbine power generation hybrid system structure and capacity matching [J]. Solar Energy, 2007 (02): 189-195.

Bao, N.S. et al. 2006. Gas turbine hybrid power generation system characteristic analysis of wind power [J]. Shenyang University of Technology, 2006 (06): 675-680.

Chen, Y et al. 2009. Wind power and photovoltaic power generation and research [D]. Network Problem.

Del Granado, P.C. et al. 2016. Synergy of smart grids and hybrid distributed generation on the value of energy storage [J]. Applied Energy, 2016.

Fathima, A.H. et al. 2015. Optimization in microgrids with hybrid energy systems--A review [J]. Renewable and Sustainable Energy Reviews, 2015,45:431-446.

Gao, Z. et al. 2014. Scenery storage hybrid solar power generation system research [D]. North China Electric Power University (Beijing) in North China Electric Power University, 2014.

Giraud, F. et al. 2001. Steady-state performance of a gridconnected rooftop hybrid wind-photovoltaic power system with battery storage [J]. Energy Conversion, IEEE Transactions on, 2001,16(1):1-7.

Ismail, M.S. et al. 2015. Effective utilization of excess energy in standalone hybrid renewable energy systems for improving comfort ability and reducing cost of energy: A review and analysis[J]. Renewable and Sustainable Energy Reviews, 2015,42:726-734.

Ke, R.Y. et al. 2013. Microgrid typical power supply mode and optimize the allocation of research [D]. Zhejiang University, 2013.

Li, C.B. et al. 2011. Conformity assessment of low-carbon energy generation scheduling and dispatching generation [J]. Chinese CSEE, 2011,31 (31): 94-101.

Mao, M.Q. et al. 2003. Wind / photovoltaic power generation system becomes complex structure simulation modeling [J]. Journal of System Simulation, 2003 (03): 361-364.

Medsker, L.R. 2012. Hybrid intelligent systems [M]. Springer Science $\backslash \&$ Business Media, 2012.

Sattler, D.R.N.C. 2015. Hybrid Sensible/Thermochemical Storage of Solar Energy in Cascades of Redox-Oxide-PairBased Porous Ceramics, 2015[C].

Shahidehpour, M \& Schwartz F. 2004. Don't let the sun down on PV [J]. IEEE Power \& Energy Magazine, 2004.

Shao, H. et al. 2013. CCHP micro-grid PV systems with optimized scheduling scheme [J]. Systems EPSA, 2013 (04): 150-155.

TuYi-Long C. 2007. Evaluation of Monthly Capacity Factor of WECS Using Chronological and Probabilistic Wind Speed Data:A Case Study of Taiwan[J]. Renewable Energy, 2007(32).
Wang, T. 2009. Study of Small Wind Power Generation System Controller [D]. Hefei: Hefei University of Technology, 2009.

Wu, Z.Q. \& Yang X.G. 2013. Affect the output characteristic function of wind turbine capacity coefficient [J]. Systems EPSA, 2013 (6): 84-86.

Xiong, Y. et al. 2015. Scenery storage and solar power generation of CCHP coordination optimization model and method [J]. Chinese Society for Electrical Engineering, 2015 (14): 3616-3625.

Zhang, X.L. et al. 2012. Output power factors of photovoltaic power plants [J]. Power System and Clean Energy, 2012, vol. 28 (Section 5): 75-81.

Zhao, B. et al. 2010. Photovoltaic power generation system output power calculation [J]. Power System and Clean Energy, 2010 (07): 19-24.

Zhou, W. et al. 2010. Current status of research on optimum sizing of stand-alone hybrid solar--wind power generation systems[J]. Applied Energy, 2010,87(2):380-389. 